\title{
Preparing MSW Students to Provide Integrated Behavioral Health Services in Rural Communities: The Importance of Relationships in Knowledge- Building and Practice
}

\author{
Carrie W. Rishel \\ Helen P. Hartnett \\ Brandi L. Davis
}

\begin{abstract}
The provision of behavioral health care services is dramatically changing. Specific components of the Affordable Care Act (ACA) encourage states to develop integrated models of service delivery that emphasize preventative services. This shift prompts the need for providers who understand the interrelationship among physical and behavioral health and who are prepared to practice in an interprofessional and teambased approach. This article presents preliminary evaluation results from the initial implementation of the Integrated Mental and Behavioral Health Training Program (IMBTP) within an MSW program which emphasizes rural practice. The IMBTP is funded through federal grants aimed at increasing the number of behavioral health providers nationwide. Results suggest that an intentional focus on relationships enhances the knowledge-building and skill development that are inherently emphasized in most training programs. Including opportunities for relationship-building both among trainees and with program faculty, clinical supervisors, and interprofessional colleagues may improve learning outcomes in behavioral health training programs.
\end{abstract}

Keywords: Behavioral health services; behavioral health training; integrated health; workforce development; rural practice; social work education

Behavioral health services are becoming more widely accepted as an integral component of overall health and well-being. Estimates indicate that approximately $20 \%$ of adults and children meet criteria for at least one behavioral health disorder (Substance Abuse and Mental Health Services Administration [SAMHSA], 2013), and nearly 50\% of the population will develop at least one behavioral health disorder in their lifetime (Kessler, Chiu, Demler, \& Walters, 2005). Behavioral health problems contribute to substantial losses in productivity and are associated with many other costly chronic diseases (Kessler et al., 2008). The National Institute of Mental Health (NIMH, 2002) estimates over $\$ 300$ billion in total annual costs associated with behavioral health problems. Exacerbating this crisis is the national shortage of providers of behavioral health services, with estimates suggesting over 90 million people live in areas designated Mental Health Professional Shortage Areas (Health Resources and Services Administration [HRSA], 2012).

Access to behavioral health services is even more limited in rural communities where qualified behavioral health providers are scarce (Rishel, Morris, Colyer, \& Gurley-Calvez, 2014). Recent work addressing the behavioral health workforce indicates that the vast majority of behavioral health professional shortage areas are rural, with $80-90 \%$ of behavioral health providers located in urban areas (Mackie, 2015). Moreover, several

Carrie W. Rishel, MSW, PhD is Professor and Helen P. Hartnett is Associate Professor, School of Social Work, West Virginia University, Morgantown, WV 26506. Brandi L. Davis, MSW is the Child \& Family Services Supervisor at the Children's Home Society, Morgantown, WV 26501. 
studies illustrate the unique challenges of recruiting and retaining rural behavioral health providers, noting limited access to resources and supervision, geographic isolation, and fewer social and professional opportunities (Mackie, 2012; Mackie \& Simpson, 2007). Efforts to address the national workforce shortage of behavioral health providers will need to specifically address these challenges in order to increase access to behavioral health services for rural populations. Predictors shown to improve hiring and retention of rural providers include: that the providers grew up in a rural area, the providers' education focused on rural concepts, and that the providers completed their internship(s) in a rural location (Mackie, 2015).

The provision of behavioral health care services is dramatically changing. Historically, mental health and substance abuse treatment have been isolated from physical health care and considered a separate sector of service. Implementation of the Patient Protection and Affordable Care Act (ACA), however, is leading to wide-scale changes in the delivery of health care services in the United States. The expansion of Medicaid and development of health insurance exchanges have led to millions more Americans accessing health insurance (Congressional Budget Office, 2012). The ACA mandates that essential benefits packages include coverage for "mental health and substance use disorder services, including behavioral health treatment" (The Patient Protection and Affordable Care Act, Sec 1302 (b)(1)(E), 2010).

New healthcare policy promotes a shift from fragmented health care delivery towards coordinated and integrated care. Specific provisions of the ACA encourage states to develop integrated models of physical and behavioral health service delivery that emphasize preventative services (Cogan 2011; Koh \& Sebelius, 2010; Wotring \& Stroul, 2011). Implementation of these policy changes has led to widespread efforts to integrate behavioral health services in primary care settings, resulting in a pressing need for more well-trained behavioral health providers (Horevitz \& Manoleas, 2013; Mechanic, 2012). The shift in service delivery prompts the need for providers in primary care, specialty treatment clinics, and behavioral health service systems who understand the interrelationship among mental health, substance use, and physical healthcare and who are prepared to address these needs through an integrated approach (Rishel, 2015).

As part of efforts to address the national shortage of behavioral health providers, the HRSA of the U.S. Department of Health and Human Services awarded Mental and Behavioral Health Education and Training (MBHET) grants to 24 programs in 2012. These 24 grants were awarded to 11 social work programs and 13 psychology programs. West Virginia University (WVU) received a MBHET grant to prepare graduate students in Master of Social Work (MSW) and doctoral psychology programs to pursue mental and behavioral health care roles with high need and high demand populations, including rural, vulnerable, or underserved populations. The training grant funded the development and implementation of the Integrated Mental and Behavioral Health Training Program (IMBTP) within the MSW program at WVU. Integrated models of service delivery are emphasized throughout IMBTP training, with interprofessional collaboration as a key component. 
The first cohort of this training program at WVU completed their MSW degree and IMBTP requirements in the spring of 2014. A comprehensive plan was established to evaluate all aspects of the training program. Due to the innovative nature of the program, one key question of interest was how training program components contributed to the overall learning experience and outcomes of the program trainees. To answer this question, qualitative data were collected from the first graduating cohort of students regarding their experiences throughout the training program. The purpose of this study was to identify what elements of an advanced training program in mental and behavioral health are most critical in achieving positive learning outcomes for participants. As current training programs expand and new ones develop, information on specific elements of training models that contribute to successful outcomes is critically needed.

\section{Overview of the Training Program}

The Integrated Mental and Behavioral Health Training Program (IMBTP) was developed with the explicit purpose of preparing students to provide high quality mental and behavioral health services with a particular emphasis on integrated models of service delivery. In the newly evolving era of health care, integrated models of practice offer the most promise in terms of effectively and efficiently meeting clients' mental and behavioral health needs. This is especially true in rural communities where financial and personnel resources may be limited and effective methods of integrating care across service sectors are necessary. While there are many possibilities for integrating services, the five emphasized in the IMBTP include the integration of: a) mental and behavioral health services with primary care, b) treatment and prevention services, c) child and parent services, d) mental health and substance abuse treatment, and e) school and community services (Rishel \& Hartnett, 2015). Content specifically addressing rural practice is addressed throughout all aspects of the training program.

The training program consists of four core elements: a) specialized field placements in mental and behavioral health settings working with rural populations; b) advanced course work in specific areas of mental and behavioral health practice; c) required training workshops targeting mental and behavioral practice knowledge and skill development; and d) continual efforts in mentorship, leadership development, professional networking opportunities, and employment placement support. Each of these components is intended to help establish relationships that support competency development. Stipend support is awarded to support trainee field placement/internship experiences via federal grant funding. One of the criteria for IMBTP field placements is the availability of strong mentorship by field instructors who have built connections with others in the local service delivery system. The field instructors are established professionals in their field, with the ability to promote trainee leadership development and foster the development of professional relationships with other leaders in the local service delivery system. An additional criterion for IMBTP field placements is the opportunity for interprofessional collaboration and teamwork. A complete description of the training program is provided in Rishel and Hartnett (2015). The program emphasizes interprofessional relationships as an important part of mental and behavioral health practice. In addition, the ability to work across disciplines and in teams is paramount to successful outcomes for clients. 


\section{The Role of Relationships in Professional Practice}

Research consistently demonstrates that who the therapist is, along with the quality of the therapeutic relationship developed with the client, impacts change outcomes far more than the model or technique applied (Duncan \& Miller, 2008). Factors associated with the therapeutic relationship are estimated to account for $30 \%$ of the change achieved in the therapeutic process (Hubble, Duncan, \& Miller, 1999). The relationship (or alliance) formed by the client and therapist is defined as an agreement between the client and therapist on goals, treatment methods, and the bond between client and therapist. Although it is typically a goal of the therapist to develop a strong therapeutic relationship, the effectiveness of the relationship is primarily based on the perception of the client rather than the perception of the therapist (Horvath \& Symonds, 1991; Shaw \& Murray, 2014). This article builds on existing literature demonstrating the importance of the therapeutic relationship in clinical outcomes by examining other types of relationships in social work practice.

Previous work suggests that what we know about the therapeutic relationship may translate to other types of relationships as well. For example, the importance of a strong relationship has been shown to be a critical component of effective clinical supervision. Early work suggests that the quality of the supervisory relationship is the most critical component of fostering positive trainee outcomes and professional development (Bordin, 1983). A more recent study reinforces early findings noting that effective clinical supervision provides a "secure and reliable base from which the trainees can explore and develop their professional identities, skills, and competencies" (Dickson, Moberly, Marshall, \& Reilly, 2010, p. 329). Additional research suggests that one of the key issues to address in clinical supervision is trainee role transition to advanced practice. Recommendations for supervisors include fostering a systemic perspective in order to assist trainees to consider the broader systemic factors that impact their roles and responsibilities in advanced practice (Sharrock, Javen, \& McDonald, 2013).

The growing movement of interprofessional education (IPE) also emphasizes the importance of relationships in preparing professionals for practice. Preparing behavioral health social workers for interprofessional team-based practice is an emerging goal in social work education (Pecukonis et al., 2013). For example, the Council on Social Work Education (CSWE) and the National Association of Social Workers (NASW) Foundation) recently implemented the Social Work HEALS (Social Work Healthcare Education and Leadership Scholars) project. The goal of Social Work HEALS is to prepare health care social workers to lead efforts to address system-level changes in the new era of healthcare (CSWE, 2015). Previous research illustrates that relationships with members of other disciplines is a key component in the development of interdisciplinary practice skills among social work students (Supiano \& Berry, 2013). Moreover, students report that training experiences that provide the opportunity to work with those from other disciplines increase their comfort level related to interprofessional practice (Pecukonis et al., 2013).

Literature addressing the therapeutic alliance, the clinical supervisory alliance, and interprofessional education all demonstrates that relationships play a key role in successful outcomes. Educational programs that prepare students for practice in mental and behavioral 
health settings should consider the importance of relationships in learning and professional practice when developing effective training strategies. This may be particularly important when preparing professionals for rural behavioral health services, as strong communitybased relationships are essential to rural practice (Daley, 2010). Fostering opportunities for relationship-building and strengthening may be an important aspect of effective training programs that is underdeveloped.

\section{Method}

The evaluation plan included both quantitative and qualitative components. The exploratory, qualitative portion of the evaluation is presented in this article. The intent was to allow the five trainees the opportunity to describe key aspects of the training in their own words. The qualitative component aimed to describe trainees' perceptions of: a) the level of knowledge and skill gained, and b) how training program elements contributed to knowledge and skill development. Data were collected just prior to students' graduation and completion of the program. The first step consisted of a free-write. To begin the freewrite, trainees were given the initial prompt, "How has the training influenced your knowledge of integrated practice?" Trainees were asked to write their responses within a 10-minute time frame. Once the time had elapsed, the second prompt "How will you take this knowledge into practice?" was read and trainees were given another 10-minute time frame. Once completed, the papers were collected and redistributed in the group. This allowed the trainees to read the responses of their fellow participants and reflect on the similarities and differences with their own responses.

The next step was a guided discussion about not only the free-write process but also about the trainee experience. This discussion lasted approximately one hour. During this discussion notes were taken for later analysis. All written responses and notes from the guided discussion were examined by two reviewers to identify themes or commonalities in experience using constant comparison. Themes were then member-checked with the group of trainees to ensure accuracy and obtain feedback. The themes that emerged from the freewrite and guided discussion are presented in the results section that follows (Kapp \& Anderson, 2010). The final step was to examine the content of field assignments in order to further refine one of the themes identified. Trainees were asked in quarterly field assignments (a total of four over the academic year) to address how the training program impacted their learning in coursework and field and their preparation for practice. Responses from these assignments were examined in order to further specify one of the themes that was unexpected. The students were also given the opportunity to participate in the preparation of this manuscript; one of the authors is a former trainee.

\section{Results}

Results reported below are based on data from: 1) the free-write and guided discussion and 2) trainee written field placement assignments. Three distinct themes emerged from the analysis of the free-write data and the guided discussion: knowledge, practice, and relationships. The intent of this phase of the evaluation was to learn from trainees' experiences in order to further develop the training program and refine the assessment processes. 


\section{Free-Write and Guided Discussion}

The first theme that emerged was knowledge. The trainees described key concepts they had learned about the meanings of integrated practice. The statements indicated that the trainees understood that integration occurs among systems, presenting problems, and across levels of social work practice (micro-mezzo-macro). These are all emphasized in the IMBTP. Examples from various respondents include:

Most of the time the client does not come in with just one issue - mental health, physical health, financial, housing problems, etc.

Integrative practice: holistic approach, multi-system, help client by addressing as many systems as possible but impossible to do all so prioritizing what is most important.

Integrative approach does not necessarily mean team approach; integrated can be involved in finding housing, medical care etc., but each agency has its own agenda and may not agree on priorities.

The second theme discussed at length by the trainees was practice. The trainees were able to provide concrete examples of what an integrated approach means in practice. As indicated by the examples provided, the trainees were able to relate the practice aspects to their field placement sites. Again, there is evidence that they understand that integration occurs across systems and across levels of practice. Examples from various respondents include:

Awareness of current practices being used, it has allowed for critical thinking about what may evolve and what may need to be tweaked to better serve clients.

To identify integrated practice within my field site such as integrating primary care and mental health services or mental health services within the school system.

Helping organizations understand and apply integrated practice. Obviously, this will be done at our place of employment. In other words, I will advocate for the use of integrated practice by educating co-workers, striving for continued knowledge regarding integrated practice, and promoting the research aspect.

Example of a hospital where all decisions are made by a team (no decision made just by a doctor) so collaborative approach and have to be 'forced to check egos at the door' and it's tough.

The final theme that emerged was relationships. While the initial themes were somewhat expected given the prompts, this theme was somewhat unexpected given the less tangible nature of this training program goal. The trainees articulated the importance of relationships, not only in the training program but also in practice. The cohort model of training was intended to foster relationships among the students, but the value and importance placed on these relationships by the trainees was an unintended outcome. As demonstrated in the literature, relationships are important to building effective therapeutic and supervisory alliances, as well as in effective interprofessional education. The trainees noted the importance of relationships in practice with colleagues: 
Need respect for all other fields - as professionals we don't necessarily respect others' points of view (as we do with different cultures, etc.) but not necessarily with other professionals.

Networking here with co-trainees - have built such strong relationships as part of this program; will call on them in the future to ask for help with professional practice issues.

Focus of seminars on integrative practice - get different perspectives from each other.

\section{Trainee Written Field Assignments}

The first two themes of knowledge and practice were somewhat expected, as the freewrite and guided discussion prompts specifically addressed these areas. The importance of relationships, however, emerged as a strong theme in the free-write and guided discussion but was unexpected as the prompts given did not specifically inquire about the impact of relationships in the training program. We felt it important to further examine this theme, as the prompts had not allowed for trainees to fully address it in their writing or discussion. Therefore, written field assignments from throughout the academic year were examined to reach a more refined understanding of the theme of relationships. Results suggest that several categories of relationships positively impacted the trainee learning experience and outcomes.

Relationships with Co-Trainees. Providing opportunities for building and strengthening relationships with co-trainees in the program was highlighted by participants as one of the most valuable aspects of the training experience. This sentiment is exemplified by the following written statements:

One unexpected outcome of program participation included the relationships that were developed with my cohort and the rich discussions we were able to have thanks to the ties of the training program. Looking back, many valuable moments of learning in action academic-wise took place during my interactions with the cohort.

The IMBTP has been an excellent supplement to my academic and professional goals. It has helped place me in a small, but motivated cohort that assists in helping deepen my understanding of the barriers to care that are unique to the rural community.

I really liked our last seminar and discussing some of our cases. Although supervision is great, talking with peers and receiving an outside perspective is extremely helpful. It also seemed like we were all able to decompress together.

I have also enjoyed being a mentor to the new IMBTP class; it is exciting to help them in their educational journey to reach their goals too.

Relationships with Training Program Faculty. In reflecting upon their MSW learning experience, trainees emphasized the important role of the specialized training program in their overall academic learning experience. In their role as mentors, training 
program faculty assist each student in recognizing their own potential and career interests. The outcome of these specialized mentoring relationships is illustrated in the following comments from various respondents:

At this point in [the program] I believe I feel as ready as one can feel to start conquering my post-graduation goals. When I look back on my graduate training the IMBTP was an essential piece of my academic learning experience. The workshops and clinical details have vastly helped inform my practice knowledge.

The IMBTP experience has been extremely beneficial. The focus on integrated care has highlighted the need [for and] success of this approach. Most importantly though, without the IMBTP experience, I do not know if I would have realized my desire to work with children, adolescents, and their families. For this reason alone, the IMBTP experience has been extremely beneficial for me.

Relationships with Clinical Supervisors and Colleagues. Trainee responses also highlighted the importance of their relationships with clinical supervisors and colleagues at their advanced field placement locations. Comments from various respondents related to these relationships included:

There are opportunities for a lot of interdisciplinary collaboration; even if there are not scheduled times for these interactions, many opportunities are presented organically. It has been incredibly valuable to me to share an office with psychologists and interact regularly with psychiatrists, as well as other seasoned counselors and social workers.

[The IMBTP] allowed me to be the first MSW student to obtain an internship position in the Mental Health Outpatient Clinic at this facility, where I had an optimal learning experience with opportunities to work with a variety of clients, practice settings and feel more than prepared to begin my professional career.

[I] build alliances with other providers by showing them the importance of working with every entity involved with the client.

Professional Relationships. Trainees are provided with multiple opportunities for professional networking throughout the training program, including attending at least two training workshops per year and presenting at the state chapter of the National Association of Social Workers' (NASW) continuing education annual conference at the end of their advanced year. For trainees, this culminating experience provides both an opportunity to share lessons learned from their training and to network with potential employers as they approach graduation. This focus on the development of professional relationships is exemplified in the following trainee statements:

I feel that there are many resources, both tangible (like clinical workbooks, manuals, etc.) and intangible (attending trainings, IMBTP-specific seminars, and workshops, etc.) and the final opportunity to present at our state Social Work Conference that have provided a truly unique opportunity and helped me begin to show professionals my goals in a more visible way, even before I graduate. I would not have had any of these opportunities had it not been for this program. 
I am eager to use our experience and build on all we've learned to give a succinct presentation at the end of our Master's program. I feel like that will kind of be a turning point, being able to organize/gather all that we've learned and disseminate it with others at the state conference.

Drawing from experience with the development, implementation, and evaluation of the IMBTP, it appears that the purposeful fostering of relationships in several areas of the program contributed to successful outcomes for the first cohort of graduates. Program graduates were deemed successful in that the overall goal, i.e., that graduates would secure post-graduation employment in mental and behavioral health settings serving their target population, was met. At the time this article was written, all five of the trainees who had completed the MSW and IMBTP programs secured employment following graduation in positions where they provide mental and behavioral health services in rural areas. At this point, the extent and role of interprofessional relationships in post-graduation employment is not yet clear. Future work will examine how the training focus on interprofessional relationships affects post-graduation employment experiences of trainees.

\section{Discussion}

Prior to discussing the results of this study, it is important to note the study's limitations. The first cohort of five trainees participated in this evaluation. The group was few in number, all located on the same campus setting, and formed a strong bond early in the training experience. This may have decreased diversity in thought and expression, narrowing the range of responses. Nonetheless, the information gathered from these processes is valuable in creating and evaluating future training programs.

Feedback from participants indicate they perceive relationships to be a key component in the success of their training. While educators might expect that two of the three themes identified in this study (knowledge and practice) would be critical aspects of successful training programs, the purposeful fostering of relationships may not typically be considered in training program development and implementation. This might be especially relevant to the practice of integrated mental and behavioral health that requires collaborative and cooperative work across disciplines and in teams. Results suggest that relationships formed as part of the training program played a key role in supporting the knowledge and practice skills identified as the two other themes in this study. Comments shared by the trainees, both as part of the focus group discussion and from their advanced field written assignments, illustrate how relationships were instrumental in both their learning (building knowledge) and their implementation of this knowledge in their field placement settings (practice). The following discussion outlines examples of the strategies employed to foster and develop the various types of relationships highlighted in trainee responses.

\section{Relationship-Building in the Rural Context}

The training program was implemented in a rural state within a graduate program that focuses on practice in small towns and rural communities. While the development of strong relationships is likely important in many types of training programs, it may be particularly 
instrumental in rural settings in which building strong relationships is an inherent part of effective practice. The statewide network of social service professionals is relatively small in a rural state and is interconnected in a variety of ways. Strong relationships initiated as part of the training program are expected to be an asset to trainees as they move on to professional positions within the state and region. Training within the program focuses on the rural context of practice; this context is recognized by trainees as illustrated by the following trainee statement:

The majority of our clients are from rural areas of [the state] and there are very few facilities like [this one] in their areas/state that can assist these clients. Additionally, the environment of our clients reflects rural Appalachian culture.

All of the types of relationships highlighted and comments by trainees should be considered within the rural context in which they occurred.

\section{Fostering Relationships With Co-Trainees}

One of the major strategies used in the IMBTP to foster relationships among the cohort is the facilitation of IMBTP-specific advanced field seminars during the trainees' final year in the program. The IMBTP project director (first author) served as the faculty field liaison for the five students in this cohort. Each of the four advanced field seminars throughout the academic year focused on various models of integrated practice and provided trainees with an opportunity to discuss specific ways to apply integrated models of service delivery in their field placement experiences. In the open-ended discussion following the free-write activity, trainees identified these advanced field seminars as instrumental in facilitating cohort cohesiveness and mutual support.

Additional strategies to foster relationships among co-trainees included small group advising sessions facilitated by the project director, cohort collaboration on a final presentation of their learning outcomes at the state NASW conference, and an electronic mailing list used to facilitate communication about IMBTP-related training opportunities. The purposeful fostering of these relationships by program faculty led to trainee-initiated relationship-building as well. Among the first graduating cohort, trainees often went to lunch together between classes, traveled together to attend training workshops, and created peer consultation meetings at specific field placement settings.

\section{Fostering Relationships With Program Faculty}

The project director of the IMBTP served as the formal academic advisor for all IMBTP trainees, and more informally, as their mentor. Much of the mentoring relationship development overlapped with the fostering of relationships among co-trainees as the mentor met with all trainees in each cohort through small group advising sessions and advanced field seminar meetings. Small group advising occurred, on average, once per semester for two hours each session. Advanced field seminars occurred twice per semester in the advanced year for three hours each session. In addition to these group experiences, the mentor met individually with trainees as needed, including visiting trainees in extended campus sites and/or arranging periodic phone meetings. In the role of faculty field liaison, the mentor visited each trainee at their advanced placement site twice during the academic 
year. Other faculty members who were closely involved with the implementation of the IMBTP also served as informal mentors with trainees, including the MSW program director and the field education coordinator. Each of these faculty members provided additional mentoring to IMBTP trainees throughout their tenure in the program and worked collaboratively with the IMBTP director to ensure their training needs were met.

\section{Fostering Relationships With Clinical Supervisors and Colleagues}

Promoting strong relationships within the field placement site was proactively addressed through the IMBTP field placement selection process. Two of the five criteria of field placement selection included relationship-based components. Specifically, placement sites must offer opportunities for interprofessional collaboration and teamwork and provide strong mentorship by field instructors and connection with leaders in the local service delivery system. The project director and field placement coordinator worked collaboratively with trainees in the field placement selection process to ensure these components were included in each IMBTP field placement experience. All IMBTP field instructors were added to an IMBTP electronic mailing list and received program updates and information regarding IMBTP-related training opportunities. Another strategy used to strengthen relationships with clinical supervisors was to offer free continuing education credits as part of the IMBTP's co-sponsored specialized training workshops with the School's Office of Professional and Community Education. These workshops were offered at no cost to IMBTP trainees and their field instructors and further promoted integration of field instructors and trainees within IMBTP training opportunities. Informal feedback suggests that the free continuing education credits (two to four full days of training annually) were a valuable benefit to field instructors and assisted in the recruitment and retention of quality field instructors for the program.

\section{Fostering Professional Relationships}

Trainees were provided with multiple opportunities for professional networking throughout the training program. All trainees attended at least two training workshops per year. These workshops were open to the wider professional community through the School of Social Work's Professional and Community Education program. Trainees were introduced at the workshops and had the opportunity to network with the greater social service community. Trainees also presented at a large, state-wide social work conference with their cohort, highlighting their learning throughout the IMBTP and how it applies to rural practice.

\section{Implications}

A large body of literature documents the important role of relationships in achieving positive outcomes in therapeutic settings, clinical supervision, and interprofessional education. Results from this preliminary study regarding specific elements of an advanced training program suggest that relationships play an important role in successful training programs as well. Previous work identifies trainee role transition to advanced practice as one of the key areas to address in clinical supervision (Sharrock et al., 2013). Trainee feedback illustrates that relationships formed with fellow trainees, as well as with other 
professionals, were instrumental in supporting this role transition to advanced practice. Based on these initial findings, the authors plan to continue to proactively foster relationship-building throughout all aspects of the training program. The MSW program that houses the IMBTP serves students in six campus locations across the state. The five graduates from the first cohort happened to all attend the main campus setting and met face-to-face for seminar activities. For subsequent IMBTP cohorts, in which some trainees are based in extended campus locations, Skype is being used via large monitor screens placed in seminar rooms at various campus sites so trainees in all sites can connect in real time and participate in seminar discussions. As the evaluation of the effectiveness of the training program continues, the authors will be especially cognizant of the use of technology to connect trainees and its impact on trainee learning outcomes.

In response to increased federal funding, more programs focused on preparing students for behavioral health practice are developing nationwide (see HRSA, n.d.). Results from this study may be used to inform decisions regarding specific components that contribute to successful outcomes. Results suggest that a focus on fostering relationships among trainees, with program faculty, clinical supervisors and interprofessional colleagues, and networking with the broader behavioral health and social service community enhances the knowledge-building and skill development that are inherently emphasized in most training programs. Future research should examine the importance of relationships in students' educational and practice outcomes with larger and more diverse samples. Studies using control groups and quantitative measures assessing interprofessional teamwork and relationship quality would further this area of scholarship.

\section{References}

Bordin, E. S. (1983). Supervision in counseling: II. Contemporary models of supervision: A working alliance based model of supervisions. Counseling Psychologist, 11, 35-42. doi:http://dx.doi.org/10.1177/0011000083111007

Cogan Jr, J. A. (2011). The Affordable Care Act's preventive services mandate: Breaking down the barriers to nationwide access to preventive services. Journal of Law, Medicine, \& Ethics, 39, 355-365. doi:http://dx.doi.org/10.1111/j.1748720X.2011.00605.X

Congressional Budget Office. (2012). Estimates for the Insurance Coverage Provisions of the Affordable Care Act Updated for the Recent Supreme Court Decision. Washington DC: Author. Accessed March 26, 2016, from http://www.cbo.gov/sites/default/files/cbofiles/attachments/43472-07-24-2012CoverageEstimates.pdf

Council on Social Work Education [CSWE]. (2015). Social Work HEALS: Social Work Healthcare Education and Leadership Scholars. Accessed March 26, 2016, from http://www.cswe.org/CentersInitiatives/ScholarshipsandFellowships/79270.aspx

Daley, M. R. (2010). A conceptual model for rural social work. Contemporary Rural Social Work Practice, 2, 1-7. 
Dickson, J. M., Moberly, N. J., Marshall, Y., \& Reilly, J. (2010). Attachment style and its relationship to working alliance in the supervision of British clinical psychology trainees. Clinical Psychology and Psychotherapy, 18, 322-330. doi:http://dx.doi.org/10.1002/cpp.715

Duncan, B., \& Miller, S. D. (2008). 'When I'm good, I'm very good, but when I'm bad I'm better': A new mantra for psychotherapists. Psychotherapy in Australia, 15, 6271.

Horevitz, E., \& Manoleas, P. (2013). Professional competencies and training needs of professional social workers in integrated behavioral health in primary care. Social Work in Health Care, 52, 752-787. doi:http://dx.doi.org/10.1080/00981389.2013.791362

Horvath, A. O., \& Symonds, B. D. (1991). Relation between working alliance and outcome in psychotherapy: A meta- analysis. Journal of Counselling Psychology, 38, 139-149. doi:http://dx.doi.org/10.1037/0022-0167.38.2.139

Hubble, M. A., Duncan, B. L., \& Miller, S. D. (1999). The heart and soul of change: What works in therapy? Washington DC: American Psychological Association. doi:http://dx.doi.org/10.1037/11132-000

Kapp. S., \& Anderson, G. (2010). Agency-based program evaluation: Lessons from practice. Thousand Oaks, CA: Sage.

Kessler, R. C., Chiu, W. T., Demler, O., \& Walters, E. E. (2005). Prevalence, severity, and comorbidity of 12-month DSM-IV disorders in the National Comorbidity Survey Replication. Archives of General Psychiatry, 62, 617-627. doi:http://dx.doi.org/10.1001/archpsyc.62.6.617

Kessler, R. C., Heeringa, S., Lakoma, M.D., Petukhova, M., Rupp, A. E., Schoenbaum, M.,...Zaslavsky, A. M. (2008). The individual-level and societal-level effects of mental disorders on earnings in the United States: Results from the National Comorbidity Survey Replications. American Journal of Psychiatry, 165, 703-711. doi:http://dx.doi.org/10.1176/appi.ajp.2008.08010126

Koh, H. K., \& Sebelius, K. G. (2010). Promoting prevention through the Affordable Care Act. New England Journal of Medicine, 363, 1296-1299. doi:http://dx.doi.org/10.1056/NEJMp1008560

Mackie, P. F. E. (2012). Social work in a very rural place: A study of practitioners in the Upper Peninsula of Michigan. Journal of Contemporary Rural Social Work, 4, 63-90.

Mackie, P. F. E. (2015, November). Behavioral health workforce policy issues: A rural perspective. Paper presented at The 31st Annual Rosalynn Carter Symposium on Mental Health Policy. Atlanta, GA. Retrieved from http://cornerstone.lib.mnsu.edu/cgi/viewcontent.cgi?article $=1031 \&$ context=sowk_fac pubs 
Mackie P. F. E., \& Simpson, C. L. (2007). Factors influencing undergraduate social work students' perceptions about rural-based practice: A pilot study. Journal of Rural Mental Health, 31(2), 5-21.

Mechanic, D. (2012). Seizing opportunities under the Affordable Care Act for transforming the mental and behavioral health system. Health Affairs, 31, 376-382. doi:http://dx.doi.org/10.1377/hlthaff.2011.0623

National Institute of Mental Health. (2002). Annual total direct and indirect costs of serious mental illness. Retrieved August 27, 2014, from http://www.nimh.nih.gov/statistics/4COST_TOTAN.shtml/index.shtml

Pecukonis, E., Doyle, O., Acquavita, S., Aparicio, E., Gibbons, M., \& Vanidestine, T. (2013). Interprofessional leadership training in MCH social work. Social Work in Health Care, 52, 625-641. doi:http://dx.doi.org/10.1080/00981389.2013.792913

Rishel, C. W. (2015). Establishing a prevention-focused integrative approach to social work practice. Families in Society, 96, 125-132. doi:http://dx.doi.org/10.1606/1044$\underline{3894.2015 .96 .15}$

Rishel, C. W., \& Hartnett, H. P. (2015). Preparing MSW students to provide mental and behavioral health services to military personnel, veterans, and their families in rural settings. Journal of Social Work Education, 51(Sup1), s28-s43.

Rishel, C. W., Morris, T. L., Colyer, C., \& Gurley-Calvez, T. (2014). Preventing the residential placement of young children: A multidisciplinary investigation of challenges and opportunities in a rural state. Children and Youth Services Review, 37, 9-14. doi:http://dx.doi.org/10.1016/j.childyouth.2013.11.027

The Patient Protection and Affordable Care Act, P.L. 111-148, Sec 1302 (b)(1)(E), 111th Cong. (2010). Retrieved from https://www.congress.gov/111/plaws/publ148/PLAW$111 \mathrm{publ148.pdf}$

Sharrock, J., Javen, L., \& McDonald, S. (2013). Clinical supervision for transition to advanced practice. Perspectives in Psychiatric Care, 49, 118-125. doi:http://dx.doi.org/10.1111/ppc.12003

Shaw, S. L., \& Murray, K. W. (2014). Monitoring alliance and outcome with client feedback measures. Journal of Mental Health Counseling, 36, 43-57. doi:http://dx.doi.org/10.17744/mehc.36.1.n5g64t3014231862

Substance Abuse and Mental Health Services Administration [SAMHSA]. (2013). Results from the 2012 National Survey on Drug Use and Health: Mental health findings, NSDUH Series H-47, HHS Publication No. (SMA) 13-4805. Rockville, MD: Retrieved August 18, 2014, from http://www.samhsa.gov/data/NSDUH/2k12MH_FindingsandDetTables/2K12MHF/N SDUHmhfr2012.htm

Supiano, K. P., \& Berry, P. H. (2013). Developing interdisciplinary skills and professional confidence in palliative care social work students. Journal of Social Work Education, 49, 387-396. 
U. S. Health Resources and Services Administration [US-HRSA]. (n.d.). Mental/Behavioral Health SAMHSA - HRSA Collaborative Grants. Retrieved June 14, 2016, from http://bhpr.hrsa.gov/grants/mentalbehavioral/index.html

US-HRSA. (2012). Shortage Designation: Health professional shortage areas \& medically underserved areas/populations. Rockville, MD: Author. Retrieved August 27, 2014, from http://bhpr.hrsa.gov/shortage/

Wotring, J., \& Stroul, B. (2011). Issue brief: The intersection of health reform and systems of care for children's behavioral health care. Washington DC: Georgetown University Center for Child and Human Development, National Center for Children's Mental Health.

\section{Author note:}

Address correspondence to: Carrie Rishel, School of Social Work, West Virginia University, PO Box 6830, Morgantown, WV, 26506, 304-293-6377,

Carrie.Rishel@mail.wvu.edu

\section{Acknowledgement:}

This project was supported by the Health Resources and Services Administration (HRSA) of the U.S. Department of Health and Human Services (HHS) under M0125201, Mental and Behavioral Health Education and Training Grant. This information or content and conclusions are those of the author and should not be construed as the official position or policy of, nor should any endorsements be inferred by HRSA, HHS or the U.S. Government. 